\title{
Características tecnológicas de pães elaborados com farelo de arroz desengordurado
}

\author{
Technological characteristics of bread prepared with defatted rice bran
}

\section{Autores | Authors}

Matheus Francisco da PAZ

Roger Vasques MARQUES

Cauana SCHUMANN

Universidade Federal de Pelotas (UFPEL)

Faculdade de Agronomia Eliseu Maciel

Departamento de Ciência e Tecnologia

Agroindustrial

Núcleo de Educação Pesquisa e Extensão em Resíduos e Sustentabilidade Pelotas/RS - Brasil

e-mail: matheusfdapaz@hotmail.com rogermarquesea@gmail.com cauanaschumann@gmail.com

\section{* Luciara Bilhalva CORRÊA}

Universidade Federal de Pelotas (UFPEL)

Faculdade de Engenharia Ambiental e Sanitária

Centro de Engenharias

Rua Benjamin Constant, 989, Sala 200,

CEP: 96010-020

Pelotas/RS - Brasil

e-mail: luciarabc@gmail.com

\section{Érico Kunde CORRÊA}

Universidade Federal de Pelotas (UFPEL) Faculdade de Agronomia Eliseu Maciel Departamento de Ciência e Tecnologia Agroindustrial

Núcleo de Educação Pesquisa e Extensão em Resíduos e Sustentabilidade Pelotas/RS - Brasil e-mail: ericokundecorrea@gmail.com

*Autor Correspondente / Corresponding Author Recebido: Out. 01, 2014 Aprovado: Jul. 08, 2015

\section{Resumo}

O objetivo deste trabalho foi avaliar a substituição, em diferentes níveis (5, 10 e 15\%), da farinha de trigo por farelo de arroz desengordurado, sobre as características: capacidade de absorção de água, perda de massa ao fornear, volume específico, perfil texturométrico e cor da casca e do miolo dos pães. Os resultados demonstram que o farelo de arroz desengordurado não apresentou influência em relação à capacidade de absorção de água, em contrapartida, teve forte influência na perda do peso ao fornear, mesmo para substituições de $5 \%$. No entanto, tal substituição não afetou o volume específico ( $p>0,05)$. Resultado semelhante foi observado para o perfil de textura, onde substituições de 10 e 15\% demonstraram afetar, principalmente, a dureza dos pães analisados. Para a cor, a adição do farelo de arroz desengordurado apresentou efeito negativo para a luminosidade do miolo e da casca, principalmente em substituições superiores a $5 \%$ para casca e $10 \%$ para o miolo. Entretanto, a substituição da farinha de trigo por $5 \%$ de farelo de arroz desengordurado demonstrou uso potencial para aplicação em produtos panificáveis.

Palavras-chave: Panificação; Sustentabilidade; Subproduto; Textura.

\section{Summary}

The aim of this study was to evaluate the replacement of wheat flour by different levels of defatted rice bran (5, 10 and 15\%) on the characteristics of: water absorption capacity, weight loss on baking, specific volume, texturometric profile and the crust and crumb colour. The results showed that the defatted rice bran showed no influence on water absorption capacity, but on the other hand had a strong influence on weight loss on baking, even for $5 \%$ replacements. However, the replacement did not affect the specific volume $(p>0.05)$. A similar result was observed for the texture profile, where replacements of 10 and $15 \%$ were shown to affect mainly bread hardness. For colour, the addition of defatted rice bran had a negative effect on crumb and crust luminosity, mainly in substitutions above $5 \%$ for the shell and $10 \%$ for the crumb. Nevertheless the replacement of wheat flour by $5 \%$ defatted rice bran showed potential for application in bakery products.

Key words: Bakery; Sustainability; By-Product; Texture. 


\section{Introdução}

Nossa sociedade enfrenta o desafio de alimentar mais de sete bilhões de seres humanos em um planeta de recursos finitos. Assim, alternativas que valorizem a utilização de subprodutos na alimentação humana podem contribuir de forma decisiva para saciar a fome, bem como favorecer a almejada sustentabilidade (GODFRAY et al., 2010).

Nesse cenário, o arroz (Oryza sativa, L.) é um dos principais ingredientes da dieta humana. No processo de beneficiamento do grão, é obtido como subproduto o farelo, que tem como principal destino a alimentação animal (QUILEZ et al., 2013). Entretanto, o aproveitamento do farelo pode ser aplicado diretamente em dietas para seres humanos, favorecendo tanto a segurança alimentar como a sustentabilidade da cadeia orizícola.

Neste sentido, o farelo de arroz desengordurado (FAD) apresenta características benéficas à saúde, dentre elas, uma quantidade significativa de proteínas, fibras e aminoácidos essências e não essenciais (WANG et al., 2002). No entanto, a adição de componentes do FAD na panificação pode modificar parâmetros sensoriais importantes para a aceitação do produto mediante ao consumidor final. Dentre eles, merecem destaque a capacidade de absorção de água, o volume específico, a perda de massa ao fornear, a cor do miolo e da casca e a textura de produtos panificáveis (LAOKULDILOK et al., 2011; SAIRAM et al., 2011).

Trabalhos que investiguem a qualidade de produtos panificáveis com a utilização de FAD, avaliando os parâmetros citados em pães, ainda são escassos na literatura científica.

Nesse contexto, o presente trabalho teve por objetivo avaliar a substituição da farinha de trigo por diferentes percentuais de FAD sobre as características acima citadas dos pães obtidos em quatro formulações.

\section{Material e métodos}

\subsection{Local do experimento}

O experimento ocorreu no laboratório de Pós-Colheita, Industrialização e Qualidade de Grãos, do Departamento de Ciência e Tecnologia Agroindustrial da Universidade Federal de Pelotas, nos anos de 2012, 2013 e 2014.

\subsection{Formulação e preparo dos pães}

Os pães foram elaborados de acordo com método proposto por Gutkoski e Jacobsen Neto (2002) e Soukoulis et al. (2014), com modificações. Foram utilizados como ingredientes farinha de trigo (100\%), água (de 55 a 58\%, dependendo da capacidade de absorção de água), sal (2\%), açúcar (5\%), gordura vegetal (3\%), fermento biológico seco liofilizado (3\%) e FAD (em níveis de substituição de 5\%,10\% e 15\%). Os ingredientes foram devidamente pesados e colocados em batedeira planetária pelo método de massa direta, onde ocorreu a mistura mecânica por 6,5 minutos. Acrescentou-se o fermento biológico e misturou-se por mais 6,5 minutos, totalizando 13 minutos. A massa foi posta em repouso por 10 minutos à temperatura ambiente e, em seguida, $200 \mathrm{~g}$ desta foi moldada manualmente e disposta em um canto da forma, para evitar deformidades no processo fermentativo. As formas possuíam $7 \mathrm{~cm}$ de largura, $14 \mathrm{~cm}$ de comprimento e 4,3 cm de altura.

A fermentação ocorreu em estufa a $38^{\circ} \mathrm{C}$ por 90 minutos, sendo forneado numa temperatura de $180^{\circ} \mathrm{C}$ por 15 minutos em forno elétrico Fischer Brusque (Brasil). Os pães foram desenformados e resfriados por uma hora antes das avaliações subsequentes.

\subsection{Farelo de arroz desengordurado (FAD)}

O FAD foi obtido pelo do descascamento e polimento de grãos de arroz branco (Oryza Sativa L.), cultivar IRGA 410, em beneficiadora de bancada. $O$ polimento durou um minuto e meio para cada lote de $50 \mathrm{~g}$ de arroz. Após o beneficiamento, o farelo foi desengordurado pelo método de Sohxlet, apresentando $0 \%$ de gordura, umidade de $13,33 \%$, cinzas $10,19 \%$, proteína bruta $15,44 \%$, fibra bruta $10,35 \%$ e carboidratos totais $50,69 \%$, sendo determinados pelos métodos propostos por American Association of Cereal Chemists (AACC, 2000), onde os carboidratos foram calculados por diferença.

\subsection{Capacidade de absorção de água (CAA)}

A Capacidade de Absorção de Água (CAA) foi determinada pelo do método proposto por Glória e Regitano-D'Arce (2000), com adaptações. $1 \mathrm{~g}$ de farinha de trigo com o farelo de arroz desengordurado em diferentes proporções foi depositado em tubo previamente pesado para centrífuga, adicionado $5 \mathrm{~mL}$ de água destilada, homogeneizado em vórtex por $1 \mathrm{~min}$, deixado em temperatura ambiente (em torno de $25^{\circ} \mathrm{C}$ ) por 30 minutos e levado à centrífuga a $25^{\circ} \mathrm{C}$ por 30 minutos a $2.600 \mathrm{rpm}$ (rotações por minuto). O sobrenadante foi retirado com auxílio de pipeta de Pasteur e, em seguida, o tubo foi pesado novamente, onde a CAA foi calculada segundo a Equação 1.

$$
\operatorname{CAA}(\%)=\frac{\text { Peso }(\mathrm{g}) \text { do sedimento }}{\text { Peso da amostra seca }(\mathrm{g})} \times 100
$$

A quantidade de água utilizada em cada formulação variou conforme análise da CAA, cujos testes foram realizados apenas com farinha de trigo (padrão). Esse procedimento possibilitou determinar a quantidade 
de água conforme a textura da massa e o volume do produto. A quantidade de água adicionada para cada $100 \mathrm{~g}$ de farinha nas formulações foi determinada pela Equação 2, adaptada de Pereira (2011). Todos os pães produzidos foram elaborados em triplicata.

$$
\mathrm{V}_{1}=(\text { CAAT } / \text { CAAP }) \times V_{2}
$$

Onde: $V_{1}$ é a água a ser adicionada, CAAT é a capacidade de absorção de água do tratamento, CAAP, a capacidade de absorção de água padrão e V2 é a quantidade de água em $\mathrm{mL}$ absorvida pelo padrão. A quantidade de água adicionada nas formulações foi de: $55 \%$ para a formulação padrão (100\% farinha de trigo); 54,51\% para a formulação de 5\% de FAD; 55,60\% para $10 \%$ de FAD; e $56,93 \%$ para $15 \%$ de FAD.

\subsection{Perda de massa ao assar}

A Perda de Massa ao Assar (PMA) foi obtida utilizando a diferença entre o peso anterior e posterior ao forneamento e o resultado dividido pelo peso anterior ao forneamento.

\subsection{Volume específico dos pães}

O volume específico do produto final foi determinado por deslocamento de painço (Panicum miliaceum L.), segundo método proposto por Pizzinatto e Campagnolli (1993), calculado pela divisão do volume obtido pelo peso do produto final, obtendo um resultado $\mathrm{em}^{\mathrm{cm}} \mathrm{g}^{-1}$.

\subsection{Textura}

A textura do miolo foi determinada com analisador TA.XT plus utilizando método padrão da AACC (74-09) (AACC, 2000), cuja sonda cilíndrica de 36mm comprimiu, a uma velocidade de $1,7 \mathrm{~mm} . \mathrm{s}^{-1}, 40 \%$ do seu tamanho original, estabelecendo a dureza $(\mathrm{N})$, a flexibilidade ( $\mathrm{mm})$, a coesividade, a gomosidade $(\mathrm{N})$, a mastigabilidade $\left(\mathrm{N} . \mathrm{mm}^{-1}\right)$ e a elasticidade. Para a análise foram utilizadas três fatias centrais de $25 \mathrm{~mm}$ de espessura, totalizando 9 repetições por tratamento, considerando a elaboração de 3 pães por tratamento.

\subsection{Cor dos pães forneados}

A cor foi obtida usando o colorímetro Minolta modelo CR-310. Para medição da cor da casca, os pães foram colocados em bancada e escolhido um ponto central aleatório da casca do produto. Em seguida, foi efetuado um corte transversal no pão para mensuração da cor do miolo. A medição se deu por leitura de cores em sistema tridimensional, em um total de três eixos. O eixo vertical "L" indica luminosidade, onde 0 corresponde a preto e 100 a branco, o eixo "a" onde -60 indica verde e +60 vermelho e o eixo "b", que indica do amarelo ao azul (BORCHANI et al., 2011). Com os valores de "a" e "b" foi calculado o ângulo Hue (cor), conforme descrito por Minolta (1994).

\subsection{Análise estatística}

O delineamento experimental utilizado foi completamente casualizado, com quatro repetições, seguindo arranjo unifatorial, sendo o fator de tratamento a proporção entre farinha de trigo e farelo de arroz desengordurado (100:0\%; 95:5\%; 90:10\% e 85:15\%). Os parâmetros avaliados foram divididos em grupos: características físicas (capacidade de absorção de água; perda de massa ao assar; volume específico), perfil de textura (dureza; elasticidade; coesividade; gomosidade; mastigabilidade; flexibilidade) e perfil colorimétrico (parâmetros L e ângulo Hue). As variáveis foram normalizadas e submetidas à análise de variância pelo teste $F(p<0,05)$. Averiguando significância estatística, os dados foram avaliados por regressão não linear com ajuste aos modelos linear (Luminosidade do miolo; ângulo Hue da casca), quadrático (CCA; Vesp; Dureza; Elasticidade; Gomosidade; Mastigabilidade; Luminosidade da casca; ângulo Hue do miolo) e cúbico (PMA; Flexibilidade) utilizando as Equações 3 e 4, respectivamente.

$$
\begin{aligned}
& y=y_{0}+a x \\
& y=y_{0}+a x+b x^{2}
\end{aligned}
$$

Onde "y" foi o parâmetro resposta avaliado, " $x$ " foi a proporção de FAD utilizada na elaboração dos pães, "a; b; c" são as constantes das equações definidas pela regressão e " $y_{0}$ " foi o intercepto. As médias dos dados foram plotadas em gráfico de linha com seus respectivos intervalos de confiança e o ajuste ao modelo matemático específico foi verificado pela significância do modelo geral $(p<0,05)$ e coeficiente de determinação $R^{2}$.

\section{Resultados e discussão}

A Figura 1a ilustra que à medida que a proporção de FAD aumenta nas formulações de pães, a CAA também aumenta, ou seja, o farelo de arroz influenciou significativamente na absorção de água, variando de $176 \%$ a $185 \%$. Esses valores estão em acordo com o estudo de Delahaye et al. (2005), onde a capacidade de absorção de água se manteve constante com adições semelhantes de substituição por FAD para massas de pizza, ao passo que Sairam et al. (2011) relatam que uma adição de 15\% de FAD já interfere na capacidade de absorção de água. No entanto, estudos realizados por Delahaye et al. (2009) sobre a adição de farelo de arroz integral em pães com farinha de trigo corroboram o resultado obtido no presente estudo onde, com diferentes 
níveis de substituição, a capacidade de absorver água das farinhas não foi modificada significativamente. No entanto, há um aumento considerável de absorção de água, que pode ser explicado, principalmente, por um aumento de fibras dietéticas presentes que, por possuir grupamentos $\mathrm{OH}$, tendem a uma ligação facilitada da água com essas fibras, e, consequentemente, retêm mais água em sua matriz (DAMODARAN et al., 2010).

Em relação à perda de massa ao assar (Figura 1b), 5, 10 e 15\% de FAD não diferiram entre si ( $p>0,05)$, mas apresentaram menor perda de massa ao assar quando comparados ao pão padrão (p>0,05). Nos pães forneados, a curva mostra ascendência com inclinação descendente, ou seja, à medida que o percentual de farelo foi adicionado nas formulações, o percentual de FAD influenciou. Contudo, com $0 \%$ de FAD, a PMA aumentou para $12 \%$; com $5 \%$, a PMA declinou para $5 \%$; com $10 \%$ de FAD, a PMA declinou para $7 \%$; e com $15 \%$ de FAD, obteve-se 6,5\% de PMA. Esses resultados são semelhantes aos encontrados por Tuncel et al. (2014b) com uso de farelo de arroz estabilizado por infravermelho,
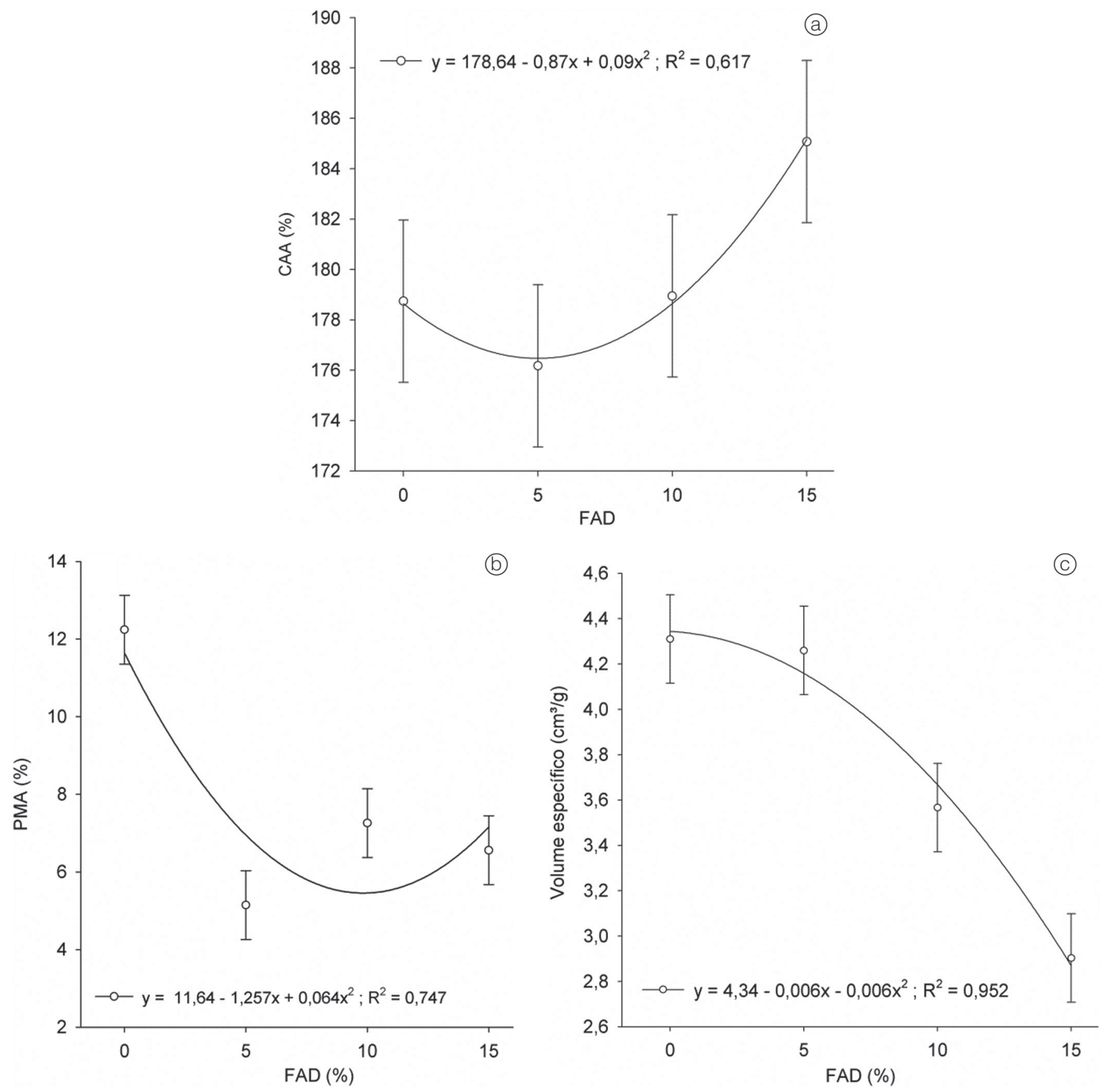

Figura 1. Gráficos dos parâmetros físicos dos pães elaborados com farelo de arroz desengordurado, capacidade de absorção de água das farinhas - CAA (a), perda de massa ao assar - PMA (b) e volume específico - VE (c). 
onde a inclusão de farelo de arroz também resultou em uma menor perda de massa, o que pode ser justificado pela retenção de moléculas de água por fibras dietéticas (DAMODARAN et al., 2010).

Pela descontinuidade da rede de glúten, há formação de pães menos aerados, uma vez que na etapa de forneamento tende a haver uma troca inferior de calor e uma menor superfície de contato, processo que contribui para a retenção de mais água em seu interior (PALLÁRES et al., 2007).

Um estudo realizado por Jiamyangyuen et al. (2005) sobre utilização de isolado proteico de farelo de arroz na panificação, demonstrou que conforme há uma maior concentração de proteína, menor será a perda de massa após o forneamento, o que pode indicar que o perfil proteico das farinhas pode ser o principal fator de relevância nesse parâmetro, considerando que o FAD agrega conteúdo proteico significativo nos produtos de panificação, proteínas exógenas que não são comprometidas para formação de rede de glúten, portanto, livres para formar complexos com a água.

A Figura 1c mostra o comportamento dos pães em relação ao volume específico, onde ilustra claramente que à medida que aumenta o teor de FAD nas formulações de pães há o declínio do volume. O único tratamento que não diferiu do controle foi o dos pães com $5 \%$ de FAD ( $p>0,05)$, já o menor volume específico observado foi com $15 \%$ de FAD $(p<0,05)$. Substituições de maior nível se mostraram desfavoráveis, diminuindo o volume dos pães conforme houve um maior acréscimo na inclusão de FAD na formulação. Os resultados são superiores aos identificados por Sairam et al. (2011), que podem variar conforme o método de panificação, força de glúten, tempo de fermentação entre outras variáveis significativas. Tuncel et al. (2014b), com uso de farelo de arroz estabilizado por infravermelho, encontraram volumes específicos na ordem de $3,50 \mathrm{~cm}^{3} \cdot \mathrm{g}^{-1}$ para substituição de $5 \%$ e 2,67 $\mathrm{cm}^{3} \cdot \mathrm{g}^{-1}$ para $10 \%$. Os valores observados no presente estudo foram superiores, o que pode ser um indicativo de que o método de extração de gordura por solvente orgânico seja mais efetivo do que o uso do infravermelho.

Segundo Abdul-Hamid e Luan (2000), a adição de 5 e 10\% de fibras dietéticas de FAD resulta em volumes específicos menores, o que pode ser explicado pela descontinuidade da rede de glúten, que a inclusão de farelo de arroz desengordurado causa. Isso também foi observado por Ajmal et al. (2006) com pães elaborados com FAD.

De acordo com Quilez et al. (2013) a fibra insolúvel é um parâmetro de extrema importância no volume específico, onde a adição de hemicelulose, advinda do FAD, interfere negativamente nesse parâmetro (HU et al., 2009), o que explica o declínio substancial no parâmetro analisado, considerando que o FAD possui mais de $10 \%$ deste componente. Um estudo realizado por Singh et al. (1995), sobre o uso de FAD e farelo de arroz integral estabilizado e não estabilizado em muffins, demonstrou que há um aumento do volume específico conforme há um aumento da substituição, contrariando os resultados obtidos e os consultados na literatura, evidenciando que os resultados podem ser influenciados pelo tipo do produto produzido, provavelmente por requerer uma continuidade do glúten menor do que em pães, ao passo que o FAD interfere justamente nessa rede proteica.

A Figura 2 mostra os resultados obtidos do perfil de textura dos pães analisados.

A curva da análise da dureza apresentou crescimento exponencial conforme a Figura $2 a$. No entanto, substituições de 5\% e 10\% não alteraram significativamente $(p>0,05)$ a dureza dos pães. O resultado encontra-se de acordo com Tuncel et al. (2014b), onde maiores valores de dureza foram encontrados com uma adição mais acentuada de farelo de arroz na panificação. Esses resultados têm sido atribuídos, principalmente, a pães com menor volume específico devido à descontinuidade do glúten, o que sugere que o $F A D$, além de descontinuar a rede proteica por meio das fibras presentes, aumenta a dureza dos pães.

Para a elasticidade, a curva foi apresentada com oscilações, conforme a Figura $2 \mathrm{~b}$. Os resultados demonstram que apenas com 10\% o FAD mostrou-se diferente do padrão. Tuncel et al. (2014b) avaliaram por infravermelho a adição de 2,5, 5,0 e 10\% de farelo de arroz estabilizado na panificação e constataram que apenas a substituição de $10 \%$ resultou em uma elasticidade menor do que a encontrada no pão padrão.

Esse resultado pode ser explicado pela relação entre a PMA e o volume específico, onde pães com $10 \%$ de FAD apresentam PMA iguais a pães com 15\% de FAD, embora com volume específico superior, o que pode indicar que mesmo com maior volume, esses pães possuem quantidade de água mais elevada e, portanto, uma elasticidade inferior nesse tratamento.

Ao tratar da coesividade, nenhum resultado diferiu do pão padrão $(p>0,05)$. Os valores encontram-se em desacordo com o consultado na literatura, na qual a panificação com uso de farelo de arroz estabilizado, em substituição de 5 e 10\%, alterou significativamente a coesividade dos pães analisados, em relação ao padrão (TUNCEL et al., 2014b), o que sugere que o farelo sem o aporte lipídico desenvolve pães menos coesos.

A análise de gomosidade foi apresentada de forma exponencial com $\mathrm{R}=0,9$, mostrando que de acordo com o aumento do percentual de FAD nas formulações, houve um aumento da gomosidade. Os resultados estão em 
desacordo com a literatura consultada, segundo a qual a gomosidade é um dos parâmetros mais afetados pela adição de farelo de arroz estabilizado, em que mesmo com a substituição de $5 \%$ já é possível perceber diferença (TUNCEL et al., 2014b).
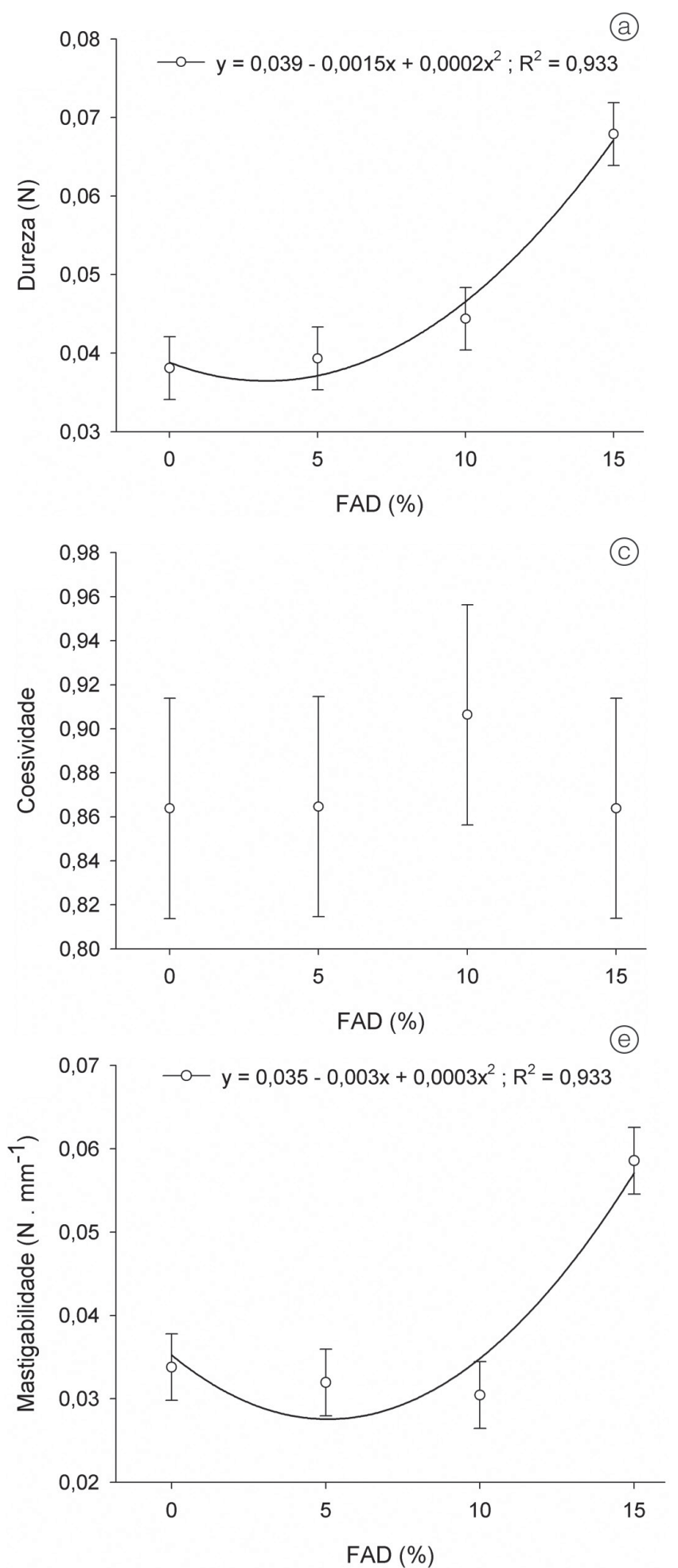

Para mastigabilidade, a curva exponencial foi apresentada com $\mathrm{R}=0,93$, ou seja, os pontos da curva para substituição do FAD influenciaram na propriedade conforme aumentou o valor nas formulações. Apenas a substituição de 15\% demonstrou afetar o parâmetro
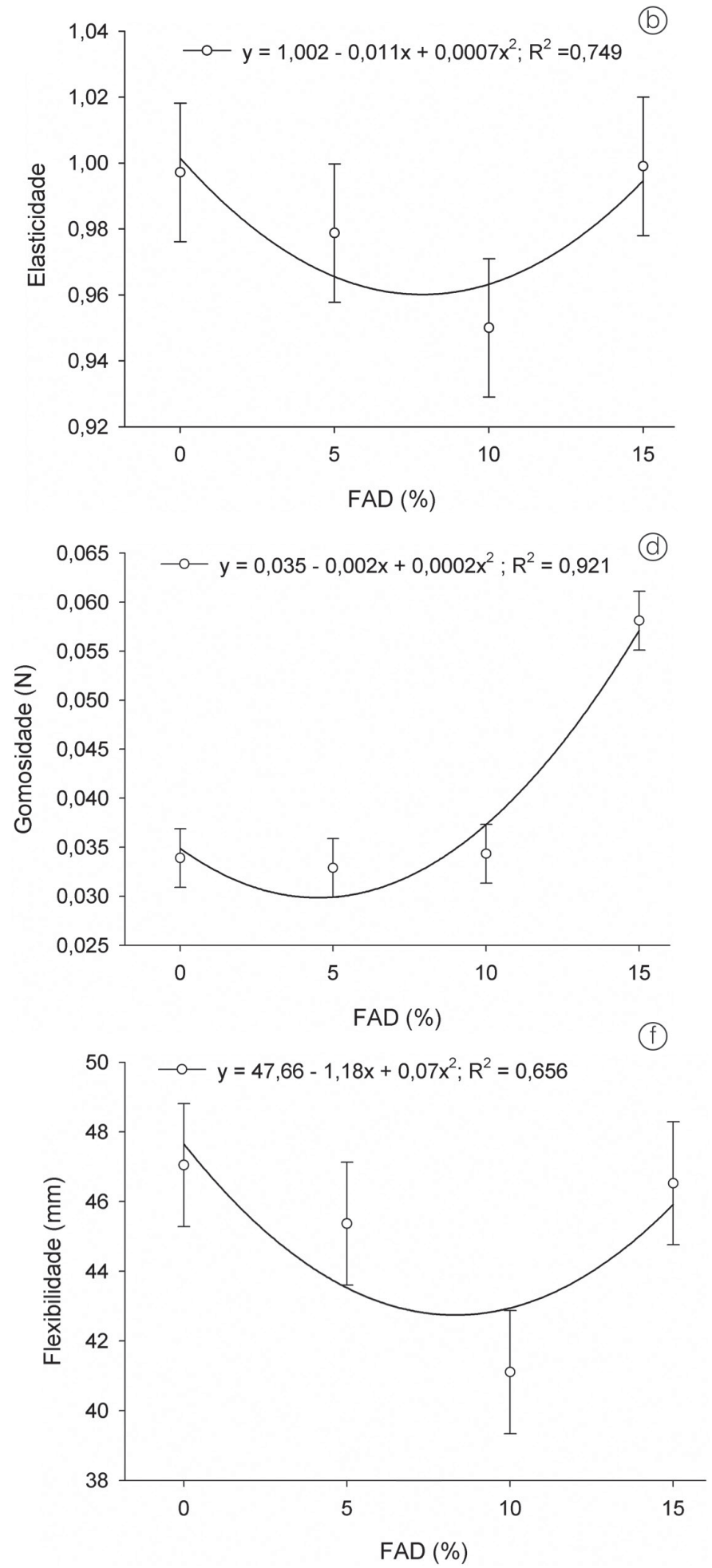

Figura 2. Propriedades de textura dos pães elaborados com FAD, sendo Dureza (a), Elasticidade (b), Coesividade (c), Gomosidade (d), Mastigabilidade (e) e Flexibilidade (f). 
analisado. Segundo Abdul-Hamid e Luan (2000), a mastigabilidade diminui conforme há uma maior adição de fibras dietéticas de FAD em produtos de panificação. Segundo Tuncel et al. (2014b) há um desacordo com os resultados obtidos, uma vez que, para os autores, mesmo adições pequenas (em torno de 5\%) de farelo de arroz estabilizado altera o parâmetro mastigabilidade.

No entanto, a adição de $3 \%$ de hemicelulose de farelo de arroz desengordurado não alterou as características de mastigabilidade de pães de trigo, ao passo que valores superiores tendem a alterar negativamente esse parâmetro (HU et al., 2009), podendo indicar que a fibra presente tem relação com a mastigabilidade, embora a alteração nesse parâmetro só tenha sido afetada com maiores concentrações de FAD.

A flexibilidade sofreu alteração somente em substituição de 10\%. Esses valores diferiram segundo a literatura consultada; mesmo com uma pequena adição de
2,5\%, os valores de flexibilidade em relação ao pão sem adição de farelo foram menores (TUNCEL et al., 2014b), o que indica que pães com FAD apresentam maior flexibilidade do que pães estabilizados de outras formas, representando melhor alternativa de uso em panificação.

Houve uma alteração global nas características de coloração $(p<0,05)$, que pode ser observada na Figura 3.

A luminosidade dos produtos obtidos variou de 69 a 76 , sendo as formulações com 5\% de FAD com $L$ de 69 e com 15\% de FAD com $L$ de 76. Para a casca, o FAD não apresentou diferença somente na substituição de 10\%, devido provavelmente à variações típicas do forneamento de pães, além da composição de aminoácidos presentes na matriz alimentar e sua influência na formação da reação de Maillard (DAMODARAN et al., 2010).

Para o miolo, houve uma diminuição significativa no parâmetro "L", onde somente a substituição de 5\% não diferiu do padrão ( $p<0,05)$. Tuncel et al. (2014b)
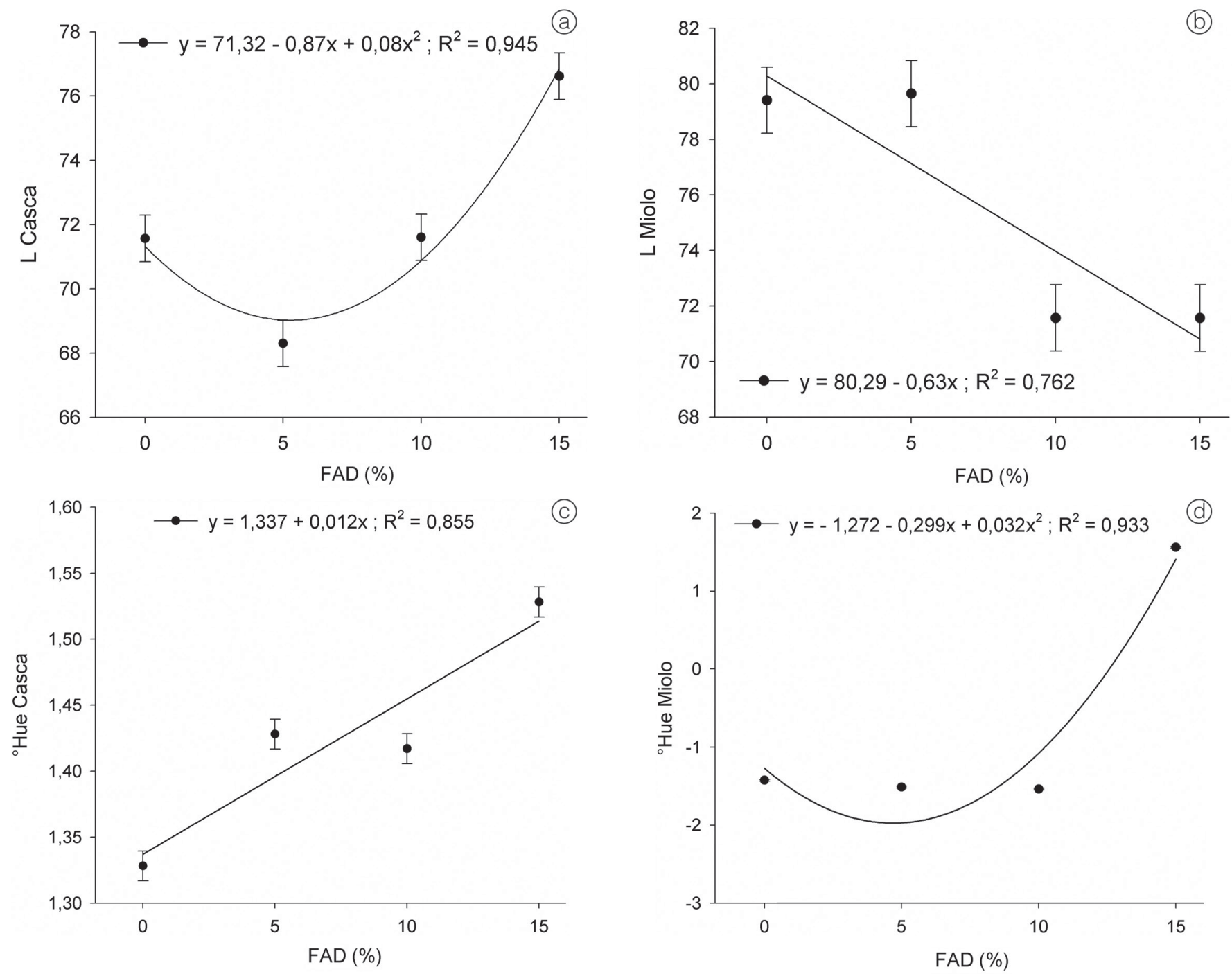

Figura 3. Perfil colorimétrico dos pães elaborados com FAD, referente ao parâmetro luminosidade da casca (a) e do miolo (b), ângulo Hue da casca (c) e do miolo (d). 
relatam uma diminuição da luminosidade do miolo conforme aumenta a concentração de farelo de arroz utilizado na formulação, com menores valores em 62,76, na substituição com 10\%.

Esses resultados estão em concordância com os consultados de literatura e podem ser explicados, principalmente, pela pigmentação natural do FAD com presença de carotenoides, que podem apresentar ação anticarcinogênica (LAOKULDILOK et al., 2011). Na literatura consultada, a adição de FAD também pode aumentar a quantidade de minerais e vitaminas presentes nos produtos de panificação (KADAN; PHILLIPPY, 2007; TUNCEL et al., 2014a).

Para o ângulo Hue da casca, todos os tratamentos diferiram do padrão, ao passo que a substituição de 5 e 10\% não diferiram entre si, porém, a substituição de $15 \%$ diferiu de todos os tratamentos, havendo um crescimento conforme maior substituição. Esses resultados podem ser explicados pela quantidade de fibras insolúveis e solúveis que interferem no processo de forneamento dos produtos, aprisionando uma quantidade de água maior e interferindo na caramelização superficial (DAMODARAN et al. 2010; PALLARÉS et al., 2007).

Para o ângulo Hue do miolo, a curva cresce exponencialmente conforme o percentual de FAD aumenta. Apenas a substituição de 15\% diferiu do padrão, o que significa que pães com maior concentração de FAD apresentaram uma coloração mais tendenciosa ao amarelo, também relacionados aos carotenoides advindos do farelo. Essa diminuição também pode ser explicada pela quantidade de fibras do FAD.

Segundo Abdul-Hamid e Luan (2000) menores escores de coloração estão associados à presença de fibras dietéticas. Esses resultados estão de acordo com os apresentados por Sairam et al. (2011), em que uma maior substituição resultou em escores menores de aceitação, tanto para a cor da casca quanto para a do miolo. No entanto, Ajmal et al. (2006) relatam que com $5 \%$ de substituição foram obtidos melhores resultados sensoriais do que o pão sem adição desse componente, não somente para coloração de miolo e casca, como também para parâmetros como sabor e textura dos pães. Os autores comentam que em baixas concentrações, o FAD pode acarretar sabores diferenciados e atrativos sem mudar totalmente o aroma do produto, o que pode indicar um bom uso do FAD em produtos de panificação.

\section{Conclusão}

Conclui-se que a substituição de farinha de trigo por FAD acima de $10 \%$ afetou as características avaliadas de panificação de capacidade de absorção de água, perda de massa ao assar, volume específico, perfil texturométrico de dureza, elasticidade, gomosidade, mastigabilidade e flexibilidade e a luminosidade e o ângulo Hue tanto da casca quanto do miolo.

Porém, a substituição em até $5 \%$ apresentou resultados promissores, não afetando a capacidade de absorção de água, o volume específico, a dureza, a elasticidade, a mastigabilidade e a flexibilidade.

Assim, os resultados obtidos neste trabalho indicam que o FAD apresenta potencial como substituinte da farinha de trigo em produtos de panificação, quando utilizado em níveis reduzidos. Porém, recomenda-se que mais investigações sobre o presente tema sejam feitas.

\section{Referências}

ABDUL-HAMID, A.; LUAN, Y. S. Functional properties of dietary fiber prepared from defatted rice bran. Food Chemistry, London, v. 68, n. 1, p. 15-19, 2000. http://dx.doi.org/10.1016/ S0308-8146(99)00145-4.

AJMAL, M.; BUTT, M. S.; SHARIF, K.; NASIR, M.; NADEEM, M. T. Preparation of fiber and mineral enriched pan bread by using defatted rice bran. International Journal of Food Properties, Muscat, v. 9, n. 4, p. 623-636, 2006. http://dx.doi. org/10.1080/10942910600580625.

AMERICAN ASSOCIATION OF CEREAL CHEMISTS - AACC. Approved methods of the American Association of Cereal Chemists. 10th. ed. St. Paul, 2000.

BORCHANI, C.; MASMOUDI, M.; BESBES, S.; ATTIA, H.; DEROANNE, C.; BLECKER, C. Effect of date flesh fiber concentrate addition on dough performance and bread quality. Journal of Texture Studies, v. 42, n. 4, p. 300-308, 2011. http:// dx.doi.org/10.1111/j.1745-4603.2010.00278.x.

DAMODARAN, S.; PARKIN, K. L.; FENNEMA, O. R. Química de alimentos de Fennema. 4. ed. Porto Alegre: Artmed, 2010. $900 \mathrm{p}$.

DELAHAYE, E. P.; JIMÉNEZ, P.; PÉREZ, E. Effect of enrichment with high content dietary fiber stabilized rice bran flour on chemical and funcional properties of storage frozen pizzas. Journal of Food Engineering, Pullman, v. 68, n. 1, p. 1-7, 2005. http://dx.doi.org/10.1016/j.jfoodeng.2004.05.048.

DELAHAYE, E. P.; PENÃ, J.; JIMÉNEZ, P. The rice bran effect on the physical-chemical and sensorial properties of wheat bread. Revista de la Facultad de Agronomía, Maracaibo, v. 26, n. 4, p. 583-598, 2009

GLÓRIA, M. M.; REGITANO-D'ARCE, M. A. B. Concentrado e isolado protéico de torta de castanha do Pará: obtenção e caracterização química e funcional. Ciência e Tecnologia de Alimentos, Campinas, v. 20, n. 2, p. 240-245, 2000. http://dx.doi. org/10.1590/S0101-20612000000200019.

GODFRAY, H. C. J.; BEDDINGTON, J. R.; CRUTE, I. R.; HADDAD, L.; LAWRENCE, D.; MUIR, J. F.; PRETTY, J.; ROBINSON, S.; THOMAS, S.; TOULMIN, C. Food security: the challenge of 
Características tecnológicas de pães elaborados com farelo de arroz desengordurado PAZ, M. F. et al.

feeding 9 billion people. Science, Washington, v. 327, n. 5967, p. $812-818,2010$.

GUTKOSKI, L. C.; JACOBSEN NETO, R. Procedimento para teste laboratorial de panificação: pão tipo forma. Ciência Rural, Santa Maria, v. 32, n. 5, p. 873-879, 2002. http://dx.doi.org/10.1590/ S0103-84782002000500021.

HU, G.; HUANG, S.; CAO, S.; MA, Z. Effect of enrichment with hemicelulose from rice bran on chemical and functional properties of bread. Food Chemistry, London, v. 115, n. 3, p. 839-842, 2009.

JIAMYANGYUEN, S.; SRIJESDARUK, V.; HARPER, W. J. Extraction of rice bran protein concetrate and its application in bread. Songklanakarin Journal of Science and Technology, Hat Yai, v. 27, n. 1, p. 55-64, 2005.

KADAN, R. S.; PHILLIPPY, B. Q. Effects of yeast and bran on phytate degradation and mineras in rice bread. Food Chemistry and Toxicology, Andover, v. 72, n. 4, p. C208-211; 2007. PMID: 17995762.

LAOKULDILOK, T.; SHOEMAKER, C. F.; JONGKAEWWATTANA, S.; TULYATHAN, V. Antioxidants and antioxidant activity of several pigmented rice brans. Journal of Agricultural and Food Chemistry, Davis, v. 59, n. 1, p. 193-199, 2011. http:// dx.doi.org/10.1021/jf103649q. PMid:21141962.

MINOLTA. Precise color communication: color control from feeling to instrumentation. Japão: Minolta, 1994. 49 p.

PALLARÉS, M. G.; LEON, A. E.; ROSELL, C. Trigo. In: LEON, A. E.; ROSELL, C. M. De tales harinas, tales panes - granos, arinas y productos de panificación en Iberoamérica. Córdoba: Hugo Báez, 2007. cap. 1. p. 17-71.

PEREIRA, J. M. Aplicação de beta-glitaca e amido oxidado de aveia em pães elaborados com farinha de arroz. 2011. $88 \mathrm{f}$. Dissertação (Mestrado em Ciência e Tecnologia de Alimentos)Faculdade de Agronomia Eliseu Maciel, Universidade Federal de Pelotas, Pelotas, 2011.
PIZZINATTO, A.; CAMPAGNOLLI, D. M. F. Avaliação tecnológica de produtos derivados de farinhas de trigo (pão, macarrão, biscoito). Campinas: ITAL, 1993. 54 p.

QUILEZ, J.; ZATOR, M.; SALAS-SALVADÓ, J.; ALVAREZ, L. Different stabilization treatments of rice bran added to wheat flour determine different properties in partially baked wheat bread. Italian Journal of Food Science. Perugia, v. 25, p. 223-228, 2013.

SAIRAM, S.; GOPALA KRISHNA, A. G.; UROOJ, A. Physicochemical characteristics of defatted rice bran and its utilization in a bakery product. Journal of Food Science and Tecnology. Karnataka, v. 48, n. 4, p. 478-483, 2011. http://dx.doi. org/10.1007/s13197-011-0262-y. PMid:23572774.

SINGH, B.; SEKHON, K. S.; SINGH, N. Suitability of full fat and deffated rice bran obtained from Indian rice for use in food. Plant Foods for Human Nutrition, Dordrecht, v. 47, n. 3, p. 191-200, 1995.

SOUKOULIS, C.; YONEKURA, L.; GAN, H.; BEHBOUDIJOBBEHDAR, S.; PARMENTER, C.; FISK, I. Probiotic edible films as a new strategy for developing functional bakery products: The case of pan bread. Food Hydrocolloids, Oxford, v. 39, p. 231-242, 2014.

TUNCEL, N. B.; YILMAZ, N.; KOCABIYIK, H.; UYGUR, A. The effect of infrared stabilized rice bran substitution on $B$ vitamins, minerals, and phytic acid content of pan breads: part II. Journal of Cereal Science, London, v. 59, n. 2, p. 162-166, 2014a.

TUNCEL, N. B.; YILMAZ, N.; KOCABIYIK, H.; UYGUR, A. The effect of infrared stabilized rice bran substitution on physicochemical and sensory properties of pan breads: part I. Journal of Cereal Science, London, v. 59, n. 2, p. 155-161, 2014b. http://dx.doi.org/10.1016/j.jcs.2013.12.003.

WANG, J.; ROSELL, C. M.; BARBER, C. B. Effect of addition of different fibres on wheat dough performance and bread quality. Food Chemistry, London, v. 79, n. 2, p. 221-226, 2002. 